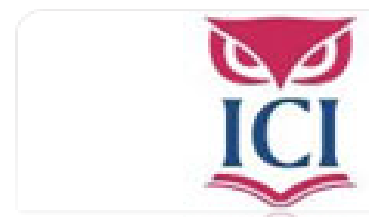

IUS. Revista del Instituto de Ciencias Jurídicas de Puebla A.C.

ISSN: 1870-2147

revista.ius@hotmail.com

Instituto de Ciencias Jurídicas de Puebla A. C.

México

Pérez Gallardo, Leonardo B.

Inseminación artificial y transferencia de preembriones post mortem: procreación y nacimiento más allá de los límites de la existencia humana

IUS. Revista del Instituto de Ciencias Jurídicas de Puebla A.C., núm. 20, 2007, pp. 139-163 Instituto de Ciencias Jurídicas de Puebla A. C.

Puebla, México 


\section{INSEMINACIÓN ARTIFICIAL Y TRANSFERENCIA \\ DE PREEMBRIONES POST MORTEM: \\ PROCREACIÓN Y NACIMIENTO MÁS ALLÁ DE LOS \\ LÍMITES DE LA EXISTENCIA HUMANA}

Leonardo B. Pérez Gallardo*

SUMARIO

I. LA EXISTENCIA HUMANA COMO LIMITE DE LA PROCREACIÓN

(PÓSTUMOS Y SUPERPÓSTUMOS EN EL SIGLO XXI)

II. La muerte del Varón como impedimento para la utilización de su "MATerial REPRODUCTOR" POR LA MUJER SOMETIDA A LA APLICACIÓN DE LAS TÉCNICAS DE REPRODUCCIÓN

ASISTIDA (EFECTOS JURIDICOS DEL QUEBRANTAMIENTO DE ESTA REGLA)

III. TODA REgLA TIENE SU EXCEPCIÓN (LA INSEMINACIÓN ARTIFICIAL POST MORTEM,

RAZONES A FAVOR Y EN CONTRA DE LOS HIJOS DE "ULTRATUMBA"

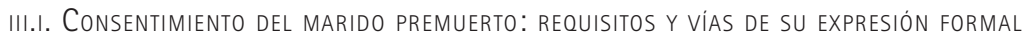

III. I.I. POR MERO DOCUMENTO PRIVAdO

III.I.II. POR ESCRITURA PÚBLICA

III.I.III. POR TESTAMENTO

III.I.IV. POR DOCUMENTO DE InStRUCCIONES PREVIAS

III.II. Aplicación tempestiva de la inseminación artificial:

EL NUEVO PLAZO ESTABLECIDO EX LEGE

III.II. EL IUS POENITENDI DEL MARIDO, SU EJERCICIO AD NUTUM

IV. La existencia de preembriones de la pareja y la presunción de "COnSentimiento" DEL MARIDO PREMUERTO PARA SU TRANSFERENCIA POST MORTEM AL ÚTERO DE LA MADRE

(CONTENIDO Y NATURALEZA DE TAL PRESUNCIÓN)

V. Posibilidad de que el varón de una pareja de hecho pueda exteriorizar su voluntad A través de los medios formales previstos ex lege. Valor de título de legitimación del documento en que Se contiene su "consentimiento" a los efectos de iniciar el eXPediente

establecido en el articulo 49 de la Ley del Registro Civil

V.I. ¿LA presunción de "CONSEntimiento" para la transferencia de preembriones post MORTEM TAMBIÉN ES APLICABLE EN PAREJAS DE HECHO?

\footnotetext{
* Doctor y profesor titular de derecho civil, Facultad de Derecho, Universidad de La Habana, Cuba. En este artículo el autor realiza algunas glosas al artículo 9 de la Ley 14/2006, de 26 de mayo, sobre técnicas de reproducción humana asistida de España.
} 


\section{RESUMEN}

El presente artículo aborda el tema de la inseminación artificial, asunto en el que se tratan diferentes supuestos que a pesar de que pueden parecer sui generis son perfectamente posibles en la realidad científica de hoy y ante los cuales el derecho debe adoptar una postura. Así por ejemplo, se analiza la inseminación artificial en la variante de que pueda suceder en vida, aunque luego sobrevenga la muerte del donante de los gametos masculino, o que pueda suceder post mortem; se valoran las confusiones generadas alrededor de que ésta suceda en condiciones in vitro o in utero, y hace amplias disquisiciones alrededor de las formas de expresión para tales efectos, bien sea a través de documento privado, escritura pública, testamento, etc. El artículo fundamenta parte de su análisis en la ley española número 14 del 2006 sobre reproducción humana asistida.

\section{ABSTRACT}

The present article approaches the topic of the artificial insemination, matter in the one that you/they are different suppositions that although they can seem particular they are perfectly possible in today's scientific reality and before those which the right of adopting a posture. This way for example, the artificial insemination is analyzed in the variant that it can happen in life, although then the death of the donor of the masculine gametes happens, or that it can happen once produced this; it is valued the confusions generated around that this happens under artificial conditions or directly in the uterus, and he/she makes wide reasonings around the expression forms for such effects, well be through private document, it notarizes public, testament, etc. The article bases part of its analysis in the Law Spanish number 14 of the 2006 on attended human reproduction.

El secreto de la felicidad no está en hacer siempre lo que se quiere, sino en querer siempre lo que se hace.

Tolstoi

\section{LA EXISTENCIA HUMANA COMO LÍMITE DE LA PROCREACIÓN (PÓSTUMOS Y SUPERPÓSTUMOS EN EL SIGLO XXI)}

Los límites de la procreación humana no sólo han estado signados por la propia existencia de los seres humanos, sino también por el periodo de fertilidad, variable según el sexo, mucho más prolongado en los hombres, que mientras viven están aptos físicamente para la procreación, $a$ contrario sensu de las mujeres, cuyo reloj cronológico se detiene, en lo que a la 
concepción concierne, por lo general durante la quinta década de vida. La aspiración de todo ser humano a tener hijos es justa y legitima; "creced y multiplicaos", reza en la Biblia. Empero, la posibilidad de conservar el semen congelado por un largo tiempo, y la fecundación in vitro con transferencia de preembriones y embriones, amén de la crioconservación de dichos preembriones y embriones ha generado dilemas no sólo éticos, sino también jurídicos, en tanto supone una ruptura de las reglas tradicionales en sede de filiación y sucesiones.

Si bien en el derecho romano se conoció el caso de hijos cuasipóstumos y póstumos, resultaba imposible el acogimiento de los hijos superpóstumos, particular hoy hecho realidad a partir de la aplicación de la inseminación artificial post mortem, un sueño irrealizable para los más connotados autores de ciencia ficción. Se trata de hijos que son procreados tras el fallecimiento de su padre, en tanto en vida de éste, con su aquiescencia, resultó congelado su semen, previa extracción. Los superpóstumos rompen con todas las reglas tradicionales que marcan las pautas para atribuir filiación, sustento de una ulterior reclamación sucesoria, en tanto filius, ergo heres. En fin, se trata de aquellos, ni tan siquiera concebidos a la muerte de su progenitor, frutos del éxito de una inseminación artificial post mortem.

\section{LA MUERTE DEL VARÓN COMO IMPEDIMENTO PARA LA UTILIZACIÓN DE SU "MATERIAL REPRODUCTOR" ${ }^{1}$ POR LA MUJER SOMETIDA A LA APLICACIÓN DE LAS TÉCNICAS DE REPRODUCCIÓN ASISTIDA (EFECTOS JURÍDICOS DEL QUEBRANTAMIENTO DE ESTA REGLA)}

Reconoce el artículo 9.1 de la actual Ley sobre técnicas de reproducción humana asistida, trasunto del precepto con igual número, contenido en la Ley 35/1988, hoy abrogada, como regla de alcance general, que la muerte del varón es un impedimento legal para la utilización de su "material reproductor" por la mujer (esposa o conviviente more uxorio), sometida a la aplicación de las técnicas. Y en efecto, ello es lógico, si la reproducción humana supone un componente binario; la ausencia de uno de sus elementos integrantes da al traste con la posibilidad de la procreación, si bien a la altura del desarrollo científico, la factibilidad de crioconservar el semen del varón supera el, hasta fecha relativamente reciente, obstáculo infranqueable. Empero, el artículo 9.1 de la Ley in commento deja escla-

\footnotetext{
${ }^{1}$ Término poco dado en el orden técnico.
} 
recido que las normas sobre filiación presuponen que el material genético masculino debe estar in utero al momento del deceso del hombre, en todo caso, sobrevendría un hijo póstumo, querido por el padre, procreado antes de su deceso, mas no nacido, sino después de la muerte de su padre, extremo que puede acontecer no sólo cuando se aplican técnicas de reproducción humana asistida, sino también en supuesto de procreación sin soporte asistido.

Si se quebrantara esta regla, se rompería con un nexo esencial, a saber: la libre decisión de procrear un hijo. Si la mujer se inseminara con el semen del varón cuya voluntad no ha sido exteriorizada, se estarían fracturando las reglas de filiación paterna. Su muerte, en principio, resulta un límite a la aplicación de cualquier tipo de técnica. De esta suerte, si a pesar de este impedimento legal se practicaran las técnicas, el hijo procreado, a pesar de que genéticamente será hijo del titular de las células reproductoras masculinas congeladas, nada podrá reclamar conforme a derecho, a su “familia paterna”, filiación de la cual carecerá.

\section{TODA REgLA TIENE SU EXCEPCIÓN (LA INSEMINACIÓN ARTIFICIAL POST MORTEM, RAZONES A FAVOR Y EN CONTRA DE LOS HIJOS DE "ULtRATUMBA")}

España desde 1988 se inscribe entre los pocos países que admiten la aplicación post mortem de las técnicas de reproducción humana asistida, lo cual ha provocado no pocas controversias doctrinales. Enconadas han sido las polémicas entre los autores españoles que han defendido o acusado la constitucionalidad de la hoy abrogada Ley $35 / 1988 .{ }^{2}$ El abanico de razones para apoyar una posición favorable o adversa en torno de los superpóstumos o hijos de ultratumba, es muy diverso. Hay quienes defienden

${ }^{2}$ Cabe citar entre ellos a Lacruz Berdejo, Roca Trías, Blasco Gascó y Pantaleón Prieto, todos cit. por María Cárcaba Fernández, Los problemas jurídicos planteados por las nuevas técnicas de procreación humana, Bosch, Barcelona, 1995, passím, cuyos argumentos seguirían sustentando a tenor de la vigente Ley 14/2006. A modo de epítome, expresa Natalia Álvarez Lata, "Cuestiones sobre el contenido atípico del testamento", pp. 12-13, en http://www.redadultosmayores.com.ar/buscador/files/B10ET005. pdf, consultado el 28 de mayo de 2007: "las discrepancias en torno a la constitucionalidad de la fecundación post mortem se sitúan en su adecuación con el contenido del Art. 39.3 cE, en tanto que tal posibilidad de procreación artificial determina en todo caso que el hijo nacido carezca de un padre que pueda prestarle la asistencia a la que se refiere el precepto constitucional. La admisibilidad de la fecundación post mortem -se ha dicho-, al apartarse de la finalidad terapéutica de las técnicas de reproducción asistida, esto es, tratar la esterilidad de la pareja, y al realizar otra finalidad, cual es la realización póstuma de la mujer de alcanzar la maternidad, contraviene la mens legislatoris del texto constitucional, en tanto que exige a los padres que presten asistencia de todo orden a los hijos, por lo que podría concluirse que con ella se transgreden los principios ordenadores de convivencia y situación familiar, condenando al hijo a una orfandad deliberada". 
la aplicación post mortem de las técnicas, sustentándolo, criterio que no comparto, en el libre desarrollo de la personalidad de la mujer, preeminente frente a un supuesto de derecho del concepturus a tener dos padres, de naturaleza bastante incierta, en tanto este aún no existe. ${ }^{3}$ Otros consideran que este precepto -refiriéndose al contenido en la abrogada Ley 35/1988, que en esencia positiviza el advenimiento de los superpóstumos-, "hace vivo al que murió a fin de seguir manteniendo la existencia de matrimonio -cuando en verdad la muerte disuelve el matrimonio- y toda esa ficción para poder calificar de matrimonial a un hijo y atribuirle las consecuencias jurídicas de tal estado". ${ }^{4}$ Se ha dicho también que con ella se pretende un imposible, esto es, hacer revivir la muerte por medio del mecanismo del niño, a través del cual se pretende prolongar la vida del padre. ${ }^{5}$ Se ha intentado encontrar en ella un marcado interés patrimonial de la viuda, como es el de poder compartir la herencia de su esposo o relegar a los, hasta ese momento, llamados a la sucesión. Una vía de traer al mundo a un hijo, condenado irremediablemente a una orfandad premeditada. ${ }^{6}$ Esto es, según arguyen con vehemencia críticos acérrimos de la permisibilidad franqueada por el artículo 9.2, como el profesor Alonso Pérez:

... ha de evitarse semejante desgracia siempre que sea posible, y en el supuesto de la fecundación post mortem, es perfectamente posible. Privar voluntariamente a un hijo de progenitor para el resto de sus días, por mucho deseo de perpetuarse o de dejar un heredero con tu propia sangre, incluso bien arropado patrimonialmente, es una jugada con las cartas en manos de un solo jugador y se presta un flaco servicio al futuro ser humano. Si de acuerdo con Segismundo, en La vida es sueño de Calderón, "el delito mayor del hombre es haber nacido", no agravemos más ese delito dejando al concepturus sin padre tan tempranamente. Si,

\footnotetext{
${ }^{3}$ Así, M. Cárcaba Fernández, Los problemas jurídicos..., Op. cit., pp. 84-85.

${ }^{4}$ Según el parecer de José Enrique Bustos Pueche, El derecho civil ante el reto de la nueva genética, Dykinson, Madrid, 1996, p. 171.

${ }^{5}$ Según R. Frydman, Op. cit. por M. Cárcaba Fernández, Los problemas jurídicos..., Op. cit., p. 82.

${ }^{6}$ Según sostiene Pasquale Stanzione, "Procreacióne assistita e categorie civilistiche", en Studi in onore di Pietro Rescigno, 1 / Diritto Privato, 1 / Persone, famiglia, successioni e propietà, Giuffrè editore, Milano, 1998, p. 865: "In relata si tratta di evitare l'hipótesis di una famiglia programmata fin dall'inizio senza la figura paterna. Sullo sfondo si muove l'inquietante prospettiva di una società senza padre." Para Juan Domínguez, "Quiero tener un huérfano”, Revista Época, 3-2-2003, en http://www.mujernueva.org/articulos/articulo.phtml?id=2683\&td=0\&tse=ANA, consultado el 28 de mayo del 2007: "No es extraño que la mayoría de los países prohíba la inseminación de mujeres sin pareja, deriva caprichosa de las técnicas contra la infertilidad. Ahora que se insiste tanto en la protección de los niños, lo lógico es no privarles de su más elemental derecho: que no se les impida tener padre y madre. Otra cosa es hacer experimentos con ellos en laboratorios creados para satisfacción de adultos.”
} 
como Séneca escribió, “a nadie le toca nacer impunemente”, más penado vendrá aún a la vida el que desde antes de su concepción ya se ve privado de la suerte inmensa de tener padre. Fabricar hijos póstumos tardíos -"ultrapóstumos"-, hijos soñados, envueltos en el doble sueño del padre que los imaginó mientras se congela su simiente de vida futura, y del hijo al que sólo le quedó soñar a lo largo de su existencia con su progenitor, viene a resultar una molesta pesadilla, cargada de frustración y de cierta responsabilidad ética. ${ }^{7}$

A fin de cuentas, a mi juicio, las posiciones muchas veces han sido de extremas. No creo halagüeño, ni provechoso, el exaltar la aplicación post mortem de la inseminación artificial, si bien el tratamiento de la fertilización in vitro con transferencia de embriones (FIVTE) debiera tener otro tratamiento, como por fortuna le atribuye el nuevo artículo 9, al superar así errores conceptuales en los que ha incurrido la propia doctrina hispana. El apartado 2 del artículo 9 tiene naturaleza excepcional; como norma de excepción debe ser tratado. Parto del supuesto de que las técnicas en su aplicación tienen un fin terapéutico y no constituyen una vía a través de la cual se puede caprichosamente obtener descendencia, mucho menos condenar premeditadamente a la orfandad paterna a un hijo. No creo que el tema se pueda calibrar sólo desde el ámbito jurídico, necesita un enfoque multi y transdisciplinario. La inseminación post mortem no sólo implica retos a la imaginación humana, a la manera en que estructuralmente tenemos diseñada la familia, sino también a los parámetros en los que concebimos la educación y formación de un hijo.

Particularmente me llama la atención el por qué los ordenamientos jurídicos europeos cierran toda posibilidad a la aplicación de la inseminación post mortem. ${ }^{8}$ Resulta paradójico que algunos países como Dinamarca

\footnotetext{
${ }^{7}$ Mariano Alonso Pérez, en Comentarios al Código Civil y Compilaciones forales, tomo xil1, volumen $2^{\circ}$, $2^{\text {a }}$ edición, dirigidos por Manuel Albaladejo y Silvia Díaz Alabart, Edersa, Madrid, 1998, pp. 17-18.

${ }^{8} \mathrm{~V}$. gr. la legislación alemana prohíbe la inseminación post mortem de forma expresa y la sueca de forma implícita, ya que el artículo 2 de la ley sobre la inseminación artificial de 1984 dice: "La inseminación artificial sólo puede realizarse con la condición de que la mujer esté casada o cohabite con un hombre en circunstancias similares al matrimonio. Debe obtenerse el consentimiento escrito del marido o compañero." Además, en el informe previo a la Ley, elaborado por el correspondiente comité gubernamental, se rechaza la inseminación artificial post mortem de forma expresa, basándose en la necesidad del niño concebido por esta técnica de tener acceso a ambos. El resto de los países no se pronuncian sobre este punto en las leyes. Vid. M., Vega, J. Vega y P. Martínez Baza, "Regulación de la reproducción asistida en el ámbito europeo. Derecho comparado”, en http://www.bioeticaweb. com/content/view/275/42/, consultado el 31 de mayo del 2007, p. 5. Cabe señalar que en países como Perú, a contrario sensu de las posiciones europeas, se pretende en el Proyecto de reformas al Libro 111 del Código Civil, incluir la aplicación de las técnicas de reproducción humana asistida con efectos
} 
sean más flexibles al acceso a las técnicas de mujeres solas y no así, en supuestos en que se pretende la aplicación tras el deceso del cónyuge o compañero. ${ }^{9} \mathrm{Ni}$ lo uno, ni lo otro, resultan los modelos idóneos de familia, pero el segundo lo creo menos nocivo que el primero. En este último sí que hay una "orfandad" premeditada, y si bien, el término no es el más apropiado, lo empleo en un sentido genérico, como ausencia perenne del rol paterno, y no sólo del padre, sino también de la familia paterna. Aquí sí que se construye un hogar monoparental, a contrario sensu de los supuestos de aplicación exitosa de la inseminación artificial post mortem. Con ello no quiero, en modo alguno, considerar digno de encomio su aplicación, pero tampoco, a mi juicio, es atinada su proscripción. En temas de esta naturaleza resulta muy riesgoso generalizar y hacer abstracciones. Vale la pena reflexionar en cada caso. El varón que expresa su voluntad, no lo hace en el sentido de que el semen congelado sea aplicado a su esposa o compañera more uxorio, sólo después de su muerte, con ese único fin, no se trata de un acto mortis causa, en todo caso de un acto post mortem, en el que alguno de sus efectos se difieren al momento de su muerte, pero en el acto de autorización para la inseminación, aun después de muerto, el hecho luctuoso no es el elemento causal-funcional. La muerte no es la ratio misma del acto, por mucho que quiera verse lo contrario. No se trata de un mero capricho de la pareja. Tampoco de buscar un heredero como los nobles y príncipes del medioevo. Mucho menos de perjudicar los derechos hereditarios de terceros; ello pudiera subyacer, no lo puedo negar, pero en todo ordenamiento jurídico la buena fe se presume y hay que actuar conforme con esa presunción, que por tener carácter iuris tantum, cabe su destrucción con prueba en contrario. La antípoda implicaría subvertir los valores axiológicos de cualquier estado de derecho. La aplicación post mortem de la inseminación artificial no vulnera principios éticos per se, no es el momento de la aplicación lo que pudiera quebrantar los valores axio-

post mortem (artículo 417.B apartado $3^{\circ}$ ). En tal sentido se llega a argüir que: "se ha contemplado la posibilidad del caso de la TERMA post mortem, tomando en consideración la existencia de los bancos de semen y que, en virtud del principio de la autonomía privada, una persona en vida decida por este tipo de técnica. Si bien ello no resulta del todo natural, resulta preciso facilitar a la viuda la descendencia de su marido utilizando su material genético dentro de un plazo (6 meses), periodo fijado con la finalidad de que el hijo nazca protegido por la presunción pater est y para evitar la zozobra o pendencia de la partición hereditaria”.

${ }^{9}$ En efecto, en Dinamarca, aunque la ley no contempla este apartado, las recomendaciones publicadas en 1990 por el Consejo ético (establecido en la legislación sobre Reproducción Asistida), también aceptan el acceso de la mujer sola a las técnicas. Vid. M. Vega, J. Vega y P. Martínez Baza, "Regulación de la reproducción asistida...”, Op. cit., p. 5. 
lógicos que informan cualquier ordenamiento jurídico, sino las razones inescrupulosas que pudieran esconderse detrás de ellas; pero esto puede acontecer con la formalización de un matrimonio, con el otorgamiento de un testamento, con la concertación de un contrato de donación y a nadie se le ha ocurrido proscribir el matrimonio, el testamento o la donación, en los textos legales.

Compete pues, a las instituciones hospitalarias, a los centros en los que se depositan los gametos masculinos, a los notarios que instrumentan los títulos formales legitimadores de la disposición post mortem del esperma congelado, el control de esa manifestación de voluntad; cabe y es preciso que así sea, que se impongan requisitos no sólo temporales, sino también de legitimación. Como se trata de una norma de excepción, valdría razonar si no es recomendable que la supérstite, viuda, o no, le competa demostrar los intentos fallidos de aplicación de las técnicas en vida de su esposo o compañero, o quizás la ausencia de hijos, o al menos de hijos comunes, la existencia de un tiempo prudencial, razonable, que demuestre esa pertinaz voluntad de procrear en ambos miembros de la pareja. Todo ello pudiera resultar valorable para acceder a la aplicación de una inseminación artificial post mortem, de modo que se trate de un acto heterónomo de voluntad, en el que no sólo incida la voluntad procreacional de los pretensos progenitores, exteriorizada, sino también la del poder público, previa justificación de los requerimientos que harían permisible una situación puramente excepcional, en la que el hijo por procrear y nacer, pueda encontrar condiciones, si no óptimas, sí al menos adecuadas para su normal desarrollo físico y psíquico.

\section{I. Consentimiento del marido premuerto: ReOUisitos y vías DE SU EXPRESIÓN FORMAL}

Ahora bien, el legislador español es diáfano en la regulación de los requerimientos formales que se exige a la manifestación de voluntad del marido premuerto, para que ésta pueda causar los efectos jurídicos, previstos ex lege. De este modo no cabe inferir dicho asentimiento por presunción legal, ni por comportamientos concluyentes (facta concludentia). En este sentido se pronunció el Tribunal Superior de Justicia de Madrid (Sala de lo Contencioso-Administrativo, sec. 9a, Sentencia No. 658 de 16 de junio del 2003, rec. 624/1998, ponente: Quesada Varea, José Luis, Ref. El derecho 2003/2220391) al desestimar el recurso contencioso-administrativo que 
interpusiera la supérstite contra la resolución del director provincial del Instituto Nacional de la Salud por la que había denegado la solicitud de la recurrente de ser inseminada con el semen de su esposo fallecido, al no concurrir los requisitos legalmente establecidos para acceder a su pretensión, no habiéndose solicitado la inseminación ni en vida de su esposo, ni dentro de los seis meses siguientes a su fallecimiento, contando con el inexcusable "consentimiento" del mismo otorgado en escritura pública. ${ }^{10}$

Por ello la forma escrita se impone como medida de seguridad. Téngase en cuenta los efectos que en el orden filiatorio, y consecuentemente, sucesorio, tiene el documento en que se manifiesta la voluntad de que la esposa sea inseminada con su esperma congelado, aun después de su muerte. De ahí que el sometimiento voluntario a las técnicas, sin que se haya llegado a constituir preembriones, no entrañe en manera alguna la asunción de una paternidad post mortem; se requiere algo más, o sea una voluntad consciente, informada, destinada a asumir tal paternidad, aun en tales circunstancias.

\footnotetext{
${ }^{10}$ En efecto, la pretensión impugnatoria deducida por la recurrente, tuvo por objeto la resolución del Insalud que denegó la petición de ser inseminada con el semen de su marido fallecido. Se suscita, por tanto, la cuestión relativa a la inseminación artificial post mortem, que rechaza el citado instituto, en este caso por diversas razones, las cuales pueden resumirse en cuatro esenciales: lo dispuesto en el artículo 9 de la Ley 35/1988, de 22 de noviembre, de Reproducción Asistida Humana, y en el artículo 7.2 b) del Real Decreto 413/1996, de 1 de marzo, así como la circunstancia de la falta de consentimiento del fallecido de tener un hijo póstumo y la no correlación del deseo de la recurrente con la finalidad principal de la mencionada Ley, que es la de solucionar la esterilidad humana. Al fallecido esposo, le había sido diagnosticada en enero de 1995 una modalidad de leucemia cuya curación requería un trasplante de médula. Tras diversas vicisitudes se señaló la intervención quirúrgica para el mes de febrero de 1996, y como quiera que o bien dicha intervención o bien la propia enfermedad, extremo que no quedó suficientemente aclarado, le producía esterilidad, hizo un depósito de semen durante los dos meses previos a la operación. Efectuada ésta en la fecha prevista, en junio de 1996 comenzaron a realizarse sobre la esposa las pruebas preparatorias de la inseminación artificial. En el mes de julio, la salud del enfermo empeoró, y falleció el 1 de agosto de ese mismo año de 1996. Al parecer, hasta el siguiente mes de noviembre continuaron practicándose ciertas pruebas médicas a la ya viuda, pruebas destinadas a la inseminación. El proceso preparatorio de la inseminación artificial concluyó definitivamente por decisión de los responsables del lnsalud en febrero de 1997. Empero, lo que llevó el asunto a sede jurisdiccional era si existía el derecho de la recurrente a inseminarse con semen de su marido, o no, a pesar de no existir una voluntad externada por escrito. En tal sentido se dispuso que: "En lo que se contrae al supuesto de autos, las partes coinciden en que no existe tal consentimiento escrito del fallecido. La eventual ausencia de información al marido y a la esposa de tales exigencias legales por parte del Insalud puede determinar, como anuncia la actora, la oportuna responsabilidad, pero en modo alguno suple ni subsana el incumplimiento de las prevenciones normativas por parte del interesado. [...] La falta de consentimiento escrito del marido fallecido, exigencia legal que no puede ignorar la Sala, conlleva la improsperabilidad de la pretensión de la actora y, por ende, la adecuación a Derecho de la resolución administrativa recurrida."
} 


\section{III.I.I. POR MERO DOCUMENTO PRIVAdo}

Esta posibilidad de exteriorizar la voluntad a través de un mero documento privado, no estaba reconocida en el artículo 9.2 de la abrogada Ley sobre técnicas de reproducción humana asistida, que tan sólo preveía el testamento y la escritura pública, aunque en el ordenamiento jurídico español cabe el otorgamiento de testamentos no públicos, como el ológrafo, que en principio constituye un documento privado, hasta tanto no se advere ante la autoridad judicial competente. Empero, el actual artículo 9.2 regula la posibilidad de que el marido pueda prestar su "consentimiento" a través del documento a que hace referencia el artículo 6.3 de la propia Ley, precepto que reconoce lo relativo al acceso a las técnicas y que literalmente dispone: "3. Si la mujer estuviera casada, se precisará, además, el consentimiento de su marido, a menos que estuvieran separados legalmente o de hecho y así conste de manera fehaciente. El consentimiento del cónyuge, prestado antes de la utilización de las técnicas, deberá reunir idénticos requisitos de expresión libre, consciente y forma." 0 sea, si bien la norma no regula taxativamente la posibilidad de que tal "consentimiento" se exprese a través de documento privado, un mero estudio sistemático de la norma nos daría la razón. La mujer que accede a las técnicas debe expresar su voluntad de aceptar la aplicación de éstas a través de un formulario de consentimiento informado, que no es sino un documento privado, según artículo 3.4 de la Ley, mientras que la del marido, que la preste antes de aplicarse las técnicas, dado que se trata de mujer casada, habrá de reunir exactos requisitos de forma, motivo por el cual deberá estar contenida en idéntico formulario. Ambas voluntades a la postre constituyen la voluntad procreacional. ${ }^{11}$ Además, la lógica indica que si la norma (artículo 9.2) prevé la escritura pública, el testamento y el

\footnotetext{
11 Por ello, coincido plenamente con el profesor M. Alonso Pérez, Comentarios..., Op. cit., xil1, $2^{\circ}$, pp. 21-22, de que estamos no frente a un acto jurídico unilateral, sino frente a un acto bilateral, pues aun post mortem, la procreación del hijo es fruto de ambas voluntades, si bien una de ellas se expresa a través de un documento previamente redactado, en el que se exterioriza tal voluntad, previéndose que en el momento en que se apliquen las técnicas, ya él no esté vivo, de modo que autoriza la utilización de su semen por su esposa, y con ello la autorización para reclamarlo del banco de semen o establecimiento especializado. Como apunta el distinguido profesor, "se trata de un negocio jurídico familiar con eficacia para después de la muerte, solemne y formal [...], de indole bilateral, pues a la voluntad de engendrar y tener un hijo por parte del padre, corresponde la de la mujer de aceptar y colaborar mediante la recepción en su útero del material genético. Las voluntades concordantes de los cónyuges difieren en el tiempo respecto de su ejecución, como es lógico, pero la colaboración bilateral de ambos es inexcusable. Negocio jurídico bilateral y familiar creador de un status filii".
} 
documento de instrucciones previas, como otras alternativas, distintas de la contenida en el artículo 6.3, es porque en tal precepto está prevista una vía más para exteriorizar la voluntad, distinta de las reconocidas expresamente en el citado artículo 9.2.

\section{III.I.II. POR ESCRITURA PÚBLICA}

Cabe también y por supuesto, con más razón, que la voluntad del marido se pueda exteriorizar a través de escritura pública. Esta posibilidad es idónea porque cuenta con el asesoramiento técnico de un notario, y con ello de un juicio de identidad, un juicio de capacidad, una fuerte presunción de autenticidad, de veracidad, de legitimación y de legalidad. La fe pública notarial hace que el documento en que se contenga la voluntad del marido sea un documento blindado en el tráfico jurídico, que presupone un negocio perfecto, en un documento también perfecto. Quien concurre ante notario, no sólo encontrará la seguridad jurídica documental, sino también la sustantiva, en tanto la voluntad exteriorizada estará plenamente informada y racionalmente exteriorizada, amén de la claridad de los términos en los que se corporifica. Esta vía es la más segura, a la vez que la más idónea, pues se trata de un documento ad hoc.

\section{III.I.III. Por testamento}

Nada priva que la voluntad sea exteriorizada a través de un testamento. Adpero, reitero que el acto por el cual se dispone del material genético reproductor, no constituye per se un acto mortis causa, y sí tan sólo un acto inter vivos, con efectos post mortem. ${ }^{12}$ Se trataría entonces de lo que se llama contenido atípico del testamento, o sea, aquel conjunto de disposiciones suficientemente numerosas, frecuentes y representativas de los diversos actos jurídicos que pueden formar parte de un testamento por disposición legal o por decisión propia del testador. ${ }^{13}$

\footnotetext{
${ }^{12}$ Sobre la distinción entre tales actos vid. lo ya dicho por mí en Derecho de sucesiones, "El acto jurídico testamentario. Contenido e interpretación”, tomo I, Félix Varela, La Habana, 2004, pp. 205-208 y los autores que allí cito.

${ }^{13}$ En relación con el contenido atípico del testamento vid. per omnia, Lourdes Fernández del Moral Domínguez, Autonomía privada y testamento en derecho común. Contribución al estudio de las disposiciones testamentarias atipicas, Comares, Granada, 1996, passím, Juan B. Jordano Barea, El testamento y su interpretación, Comares, Granada, 1999, pp. 7-13 y N. Álvarez Lata, "Cuestiones sobre el contenido...", Op. cit., passim.
} 
Ahora bien, a pesar de que ninguno de los preceptos que la Ley contiene, establezca expresamente la edad para expresar tal "consentimiento", se exigirá los 18 años, o sea, la mayoría de edad (vid. artículo 318 del Código Civil), en tanto que si para la mujer lo exige el artículo 6.1, de estar ésta casada, tal requerimiento es aplicable, a fortiori, al marido, máxime si se trata de un acto con efectos post mortem, a cuyo tenor se está autorizando la procreación de un ser humano, en ausencia incluso de su progenitor masculino. La lógica no nos pueden inducir a otra consecuencia. Por ello, le asiste razón a Álvarez Lata cuando alerta que: "De esta forma, se restringe la capacidad del que puede hacer esa disposición frente a la capacidad testamentaria general de los Arts. 662 y 663 сc que, como es sabido, no vinculan la capacidad para testar con la capacidad de obrar plena sino con el juicio suficiente para querer y entender el negocio jurídico testamentario. La repercusión inmediata de lo señalado es que el incapacitado, capaz de testar cuando cumpla los requisitos del Art. 665 cc, no podrá realizar una disposición atípica de estas características". ${ }^{14}$ Ergo, tratándose de la testamentifactio activa, será suficiente el haber arribado a los 14 años de edad, conforme con el artículo 663.1 ${ }^{\circ}$ del Código Civil, empero en sede de disponibilidad post mortem de las células germinales masculinas necesariamente tendrá que cumplimentar los 18 años de edad.

Tratándose de un testamento ológrafo o de testamentos especiales, será necesario que cumplimenten los requisitos exigidos a tal fin, y la ulterior adveración y protocolización ante notario, según las previsiones de los artículos 677, 678, 688 al 693, y 716 a 731 del Código Civil.

En relación con la posibilidad de revocación del testamento en que se contiene tal manifestación de voluntad, cabe argüir que ello no conculca la naturaleza esencialmente revocable que tiene la propia manifestación de voluntad dispositiva del esperma. Si revoca el testamento, y nada dice respecto a tal acto dispositivo, quedaría éste revocado, a menos que haya salvado expresamente su ineficacia, por su propia declaración de voluntad en tal sentido. Si actúa conforme con el artículo 739 del Código Civil, cobraría vigencia el primero de los testamentos otorgados y con ello, el acto dispositivo del esperma que en él se contiene. ${ }^{15}$

${ }^{14}$ Vid. N. Álvarez Lata, “Cuestiones sobre el contenido...”, Op. cit., p. 14.

${ }^{15}$ Con idéntico parecer, Rafael Gómez-Ferrer Sapiña, "Técnicas de reproducción asistida humana y derecho de sucesiones”, en Revista Jurídica del Notariado, No. 13, enero-marzo, 1995, pp. 231-232. 


\section{III.I.IV. POR DOCUMENTO DE INSTRUCCIONES PREVIAS}

El otro recurso formal al que acude el artículo 9.2 de la LTRA española es el documento de instrucciones previas, novedad introducida a partir de la incorporación de esta figura en el ordenamiento jurídico español, ${ }^{16}$ en el entendido de que se trata del documento en que se reconoce la declaración de voluntad de una persona con capacidad suficiente como para aceptar o rechazar tratamientos médicos extraordinarios o desproporcionados en caso en que se encuentre en situaciones límite, o sea, en un estado en que no pueda exteriorizar válidamente su voluntad, esto es, en previsión de que no pueda expresar su voluntad en un momento ulterior, por padecer alguna enfermedad degenerativa o estar en estado vegetativo persistente o en coma, tras una enfermedad o accidente. Se trata de un consentimiento informado exteriorizado anticipadamente, de ahí su nombre, para la eventualidad de un estado de inconciencia, circunstancia para la cual se nombra además un sustituto, a los fines de que constituya el interlocutor entre el emisor de la voluntad y el médico tratante.

A pesar de que la doctrina científica española que ha estudiado el tema ${ }^{17}$ no suele incluir la disponibilidad del esperma congelado, post mortem su titular, dentro del contenido del documento de voluntades anticipadas, tra-

\footnotetext{
${ }^{16}$ La doctrina científica coincide en que el punto inicial lo fue la entrada en vigor en España del Convenio de Oviedo de fecha 1 de enero del 2000, lo cual conllevó a la promulgación de un conjunto de leyes, tanto al nivel autonómico como estatal, reguladoras de las voluntades anticipadas, entre ellas cabe señalar la Ley $41 / 2002$, de 14 de noviembre, reguladora de la autonomía del paciente y de derechos y obligaciones en materia de información y documentación clínica, en vigor desde el 16 de mayo del 2002 (de carácter estatal), así como también las leyes autonómicas como la Ley 21/2000, de 29 de diciembre, sobre los derechos de información concerniente a la salud y la autonomía del paciente y la documentación clínica de Cataluña, la Ley 3/2001, de 28 de mayo, que aprueba las normas reguladoras del consentimiento informado y de la historia clínica de los pacientes, de Galicia, la ley 10/2001, de 28 de junio, sobre normas reguladoras de la salud de Extremadura, la ley 6/2002, de 15 de abril, de normas reguladoras de salud, de Aragón, la Ley 2/2002, de 17 de abril, de salud de La Rioja, Ley foral 11/2002, de 6 de mayo, de derecho del paciente a las voluntades anticipadas, a la información y a la documentación clínica, de Navarra, la Ley 7/2002, de 10 de diciembre, de ordenación sanitaria de Cantabria, la Ley $7 / 2002$, de 12 de diciembre, de voluntades anticipadas en el ámbito de la sanidad del País Vasco, la Ley $1 / 2003$, de 28 de enero, sobre derechos e información al paciente de la comunidad de Valencia, la Ley $3 / 2005$, de 23 de mayo, por la que se regula el ejercicio del derecho a formular instrucciones previas en el ámbito sanitario y se crea el registro correspondiente, de Madrid, la Ley 6/2005, de 7 de julio, de declaración de voluntades anticipadas en materia de la propia salud, de Castilla-La Mancha, y la Ley 1/2006, de 3 de marzo, de voluntades anticipadas, de lslas Baleares.

${ }^{17}$ Vale mencionar, además de los autores que se citan en las notas que siguen a la presente a: Diego Alonso Herreros, "El documento de voluntades anticipadas. Análisis de la ley holandesa sobre eutanasia”, en Revista Jurídica de Catalunya, año cl11, No. 2, 2004, pp. 65-93; Jesús María Silva Sánchez, "Los 'documentos de instrucciones previas' de los pacientes (artículo 11.1 Ley 41/2002) en el contexto del debate sobre la (in)disponibilidad de la vida”, en revista La Ley, tomo 4/2003, pp. 1663-1671.
} 
tándose de una "declaración de voluntad relativa a la expresión anticipada de los deseos del otorgante respecto de ciertas intervenciones médicas", ${ }^{18}$ cuyo "fin es suplir el consentimiento informado cuando las circunstancias no permitan al paciente expresar personalmente su voluntad", ${ }^{19}$ constituyendo "el instrumento más adecuado para dar a conocer la voluntad en cuestiones relacionadas con la propia salud y las decisiones estimadas conformes con la dignidad y la escala personal de valores", ${ }^{20}$ puede sin duda ir dirigido a diferentes finalidades, ${ }^{21}$ entre las cuales se ha incluido en el artículo 9.2, primer párrafo, de la Ley 14/2006, la disponibilidad del semen congelado, para su ulterior utilización, aun post mortem. De todos modos, se trataría de un documento otorgado, bien ante notario o ante tres testigos, o incluso, excepcionalmente, según establece alguna norma autonómica, ante el encargado del Registro de Voluntades Anticipadas (vid. artículo 3.2 inciso b) de la Ley del País Vasco), por lo cual cumplirá requerimientos formales, más solemnes en unos que en otros, por persona que sea mayor de edad, eso sí, en tanto que para acceder a las técnicas se exige este presupuesto. Tampoco cabría ripostar que las voluntades anticipadas están concebidas con exclusividad para que surtan efectos en vida de su autor, si bien en circunstancias en que éste per se no pudiera exteriorizar válidamente esa voluntad, por cuanto nada quita que forme parte de su contenido otras previsiones post mortem, a saber: las relativas a la disponibilidad de órganos y tejidos humanos, entierro, incineración, la autopsia clínica u otra similar, ${ }^{22}$ como la que se hace referencia en esta oportunidad.

\section{III.II. Aplicación tempestiva de la inSEMinación artificial: EL NUEVO PLAZO ESTABLECIDO EX LEGE}

Entre las modificaciones más significativas contenidas en la Ley sobre

${ }_{18}$ Vid. Felipe Pou Ampuero, "Testamento vital: declaración de voluntades anticipadas”, en Revista Jurídica del Notariado, No. 42, abril-junio 2002, p. 305.

${ }^{19}$ Vid. José Luis Requeiro lbáñez, "El testamento vital y las voluntades anticipadas: aproximación al ordenamiento español”, en La Ley, tomo 4, 2002, p. 1901.

${ }^{20}$ Vid. Mónica Navarro Michel, "El documento de voluntades anticipadas (el mal llamado "testamento vital')", en La Notaría, Revista del Colegio de Notarios de Cataluña, No. 2, febrero del 2003, p. 25.

${ }^{21}$ Con este parecer se pronuncia José María Segura Zurbano, "El testamento vital o de voluntades anticipadas: panorama actual”, en Boletín de Información del Ilustre Colegio Notarial de Granada (segunda época), No. 257, enero del 2003, p. 198.

${ }^{22}$ Así lo expresa, M. Navarro Michel, "El documento de voluntades...", Op. cit., p. 31, criterio que comparto. Algunas leyes autonómicas como la de Valencia, se refieren a la disponibilidad de los órganos con finalidad terapéutica, docente o investigativa (Cfr. artículo 17), en tanto en la exposición de motivos de la ley del País Vasco se incluye cualquier otra previsión vinculada con el final de la vida, entre ellas la autopsia clínica. 
técnicas de reproducción humana asistida cabe reseñar el alargamiento del plazo concedido ex lege a la viuda para intentar de modo exitoso la procreación. El plazo anterior era de seis meses, acogido por algunos, en tanto ofrecía celeridad a los herederos, cuyo derecho sucesorio podría verse disminuido o extinguido por el resultado, con éxito, de la aplicación de las técnicas. La seguridad jurídica en sede sucesoria, impulsa, sin duda, la necesidad de poner cortapisas al ejercicio dilatado en el tiempo del derecho a inseminarse. Sin embargo, el plazo concedido era, a mi juicio, demasiado breve, para un proceso no sólo complejo en el orden médico, sino porque el éxito no depende en exclusiva de la pericia médica, sino también del estado físico y psíquico en que se encuentre la viuda, de su predisposición al éxito. Suele acontecer que el fallecimiento de las personas que prevén y autorizan una inseminación post mortem, está asociado a un largo proceso de enfermedades oncológicas, donde no sólo se desgasta físicamente el enfermo, sino los familiares más propincuos, entre ellos la esposa, y estas circunstancias en nada suelen favorecer el triunfo en la aplicación de la técnica, máxime cuando ello se hace en fecha cercana al duelo, o incluso en etapa aún de duelo, con temor a que el plazo decurse, y entonces nada pueda hacerse. El plazo hoy de un año, sin lesionar los derechos de terceros, me parece atinado y justo. No pone en apuros a la viuda, ni va en desmedro de los derechos de aquellos pretensos herederos concurrentes, ${ }^{23}$ o no, ${ }^{24}$ con el superpóstumo. No obstante, hay quienes abogan por un plazo más prolongado, a mi juicio, demasiado peligroso. ${ }^{25}$ Eso si lo que queda claro es que decursado ese plazo, de aplicarse las técnicas, no cabrían efectos filiatorios, ni sucesorios, respecto del concebido, aunque el resultado de las pruebas genéticas denuncie la verdadera relación filiatoria entre el nacido y su finado padre. Extremo que algunos autores consideran discriminatorio en el orden constitucional, por afectar derechos filiatorios y sucesorios del hijo procreado extemporáneamente. ${ }^{26}$

\footnotetext{
${ }^{23}$ Como el resto de los hijos, a la postre, hermanos del superpóstumo.

${ }^{24}$ Como pudieran ser los padres o demás ascendientes, hermanos del causante, sobrinos o el resto de los colaterales, según los artículos del Código Civil.

${ }^{25}$ Sobre tal particular vid. M. Cárcaba Fernández, Los problemas jurídicos..., Op. cit., pp. 94-95 y en concreto los criterios manejados por la autora, de la doctrina española y foránea en nota 191.

${ }^{26}$ Vid. M. Cárcaba Fernández, Los problemas jurídicos..., Op. cit., pp. 90-93. Con extrema vehemencia J. E. Bustos Pueche, El derecho civil ante el reto..., Op. cit., pp. 176-177, quien considera inconstitucional el artículo 9.1 de la ley (trasunto del cual es el actual 9.1), dado que pretende impedir a un hijo la determinación de su filiación matrimonial, cuando se sabe a ciencia cierta quién fue su padre, por la razón ridícula -según apunta el autor-de inobservancia de requisitos de tiempo y forma. De esta manera lo tilda de inconstitucional, dado que el hijo procreado en estas circunstancias, se le niega el derecho de llevar los apellidos del padre que todos reputan como progenitor y, en consecuencia, de
} 
Respecto del die a quo para el cómputo del plazo de doce meses, será aquel a partir del día siguiente al fallecimiento del marido o desde la fecha en que se entiende sucedida la muerte, según lo contenido en la sentencia sobre declaración de fallecimiento, conforme con lo previsto en el artículo 195, segundo párrafo, del Código Civil. ${ }^{27}$

\section{III.III. EL IUS POENITENDI DEL MARIDO, SU EJERCICIO AD NUTUM}

El derecho de disponer del semen congelado a los fines procreacionales, puede ejercerse, eso sí, ad nutum. Nada compele al cónyuge a mantener en pie la declaración de voluntad contenida en un documento público o privado. En cualquier momento puede ejercer el ius poenitendi y destruir voluntariamente la eficacia del acto. Tal carácter forma parte de la naturaleza jurídica del acto dispositivo, aun haya sido recepcionada la voluntad del marido por la esposa. Tratándose de una disposición con efectos post mortem, mientras no sobrevenga la muerte, puede ser enteramente revocable, tanto la autorización para que el semen sea utilizado en vida, como tan sólo para que no sea empleado por la esposa, en su condición de viuda, tras su deceso; o sea, cabe que el contenido del acto revocatorio se limite, con exclusividad, a que el semen congelado sea utilizado tan sólo mientras viva su titular, habilitando a la esposa para la inseminación in vivo, no así post mortem, a pesar de que en un momento se dispuso lo contrario. El autor de la declaración de voluntad puede ir sobre sus pasos y retractarse mientras tenga vida. Siendo un derecho personalísimo, no cabría su ejercicio por su tutor o curador, si ante mortem deviene en un sujeto sometido a tutela o curatela.

El artículo 9.2, primer párrafo in fine, prevé tal posibilidad de revocación del "consentimiento"; no obstante, no regula la forma de exteriorizar dicha voluntad, lo cual hace suponer la posibilidad de revocación a través de una manera distinta a aquella en que se expresó la voluntad de disponer el esperma; incluso hay quienes sostienen la tesis de que la revocación cabría por hechos concluyentes. ${ }^{28}$

participar en su herencia.

${ }^{27}$ Pues no cabe duda que la declaración judicial de fallecimiento, tendría los mismos efectos para una posible aplicación post mortem de la inseminación artificial.

${ }^{28}$ Así, N. Álvarez Lata, “Cuestiones sobre el contenido...”, Op. cit., p. 15. 


\section{LA EXISTENCIA DE PREEMBRIONES DE LA PAREJA Y LA PRESUNCIÓN DE CONSENTIMIENTO DEL MARIDO PREMUERTO PARA SU TRANSFERENCIA POST MORTEM AL ÚTERO DE LA MADRE (CONTENIDO Y NATURALEZA DE TAL PRESUNCIÓN)}

Si hay un tema que merece ser estudiado con detenimiento en la Ley 14/2006 es precisamente el que repasaré en este apartado.

El artículo 9 de la abrogada Ley 35/1988 no era nada diáfano con la situación dada a causa del fallecimiento del varón que había manifestado su voluntad para la práctica de una FIVTE, y ya se habían obtenido preembriones. Incluso en la doctrina se manejaba dicha situación como un supuesto de fecundación post mortem, ${ }^{29} \mathrm{o}$ procreación post mortem, cuando en realidad la utilización equívoca de los términos conducía a un grave error conceptual. En estas circunstancias la procreación se había realizado in vitro, no in utero, y por supuesto ante mortem, no post mortem. Por ello el tratamiento a darse debía ser diferente al que consagraba el artículo 9 de la nombrada Ley.

La doctrina científica intentó encontrar una solución a base de una aplicación analógica, para un supuesto no reconocido expresamente $e x$ lege, empero en buena técnica jurídica se carecía de la eadem ratio que exige el artículo 4.2 del Código Civil para autointegrar el derecho a partir del procedimiento analógico, en su modalidad de analogía ex lege. Otros, más escépticos, como Bustos Pueche, negaban la posibilidad de una transferencia post mortem al útero de la madre del embrión (dígase ahora preembrión) ${ }^{30}$ crioconservado. En tal sentido, a la luz de aquel precepto

\footnotetext{
${ }^{29}$ Así lo trata Pedro J. Femenía López, Status jurídico civil del embrión humano, con especial consideración al concebido in vitro, Mc Craw Hill-Ciencias Jurídicas, Madrid, 1999, p. 278, llegando incluso a definirla, con lo cual incurre en grave en error conceptual al hablar de fecundación, cuando el embrión preimplantatorio ya está congelado, luego, ya no puede hablarse de fecundación, ni mucho menos cabe decir -como expresa el propio autor- que en tal supuesto el propósito es "engendrar un hijo de ambos”, refiriéndose al premuerto y la viuda, tal y como acontece en la inseminación post mortem. ${ }^{30}$ Tomo la distinción que reconoce ahora la vigente norma legal entre preembrión y embrión, a pesar de que el autor comentado no la tuvo en cuenta. Según el artículo 1.2. de la Ley 14/2006: "se entiende por preembrión el embrión in vitro constituido por el grupo de células resultantes de la división progresiva del ovocito desde que es fecundado hasta 14 días más tarde". Particular que ha llevado a los primeros estudiosos de la norma a expresar, no sin razón que: "La simple lectura del texto pone de manifiesto que el preembrión no es algo distinto sustancialmente de un embrión. Lo que permite aplicarle tal categoría legal es el lugar donde se encuentra in vitro, al haber sido engendrado por medios artificiales. Pero si lo es por medios naturales in vivo, entonces, literalmente, no es preembrión. No tiene mucha base biológica asumir que el resultado de la fecundación es diferente según donde suceda: de hecho, las técnicas de reproducción asistida necesariamente se basan en que es el mismo resultado". Vid. lñigo Fernández Gallardo, "Algunos aspectos sobre la nueva ley de reproducción asistida”, en El Derecho, EDO, 2006/273469.
} 
invocaba que en el ordenamiento jurídico español sí estaba justificado el término fecundación post mortem y no embarazo post mortem, este último propio de la transferencia de los preembriones a la madre, después de fallecido el marido. Para ello se apoyaba en una interpretación ad pedem litterae del artículo 9 que hablaba inequívocamente de "material reproductor masculino" y de "fecundar a su mujer con aquél". De esa manera el citado profesor se inscribía entre los que apoyaban la tesitura de la imprevisibilidad legal de que un preembrión sobrante congelado, pudiera después de la muerte del progenitor ser reclamado por la viuda para su desarrollo natural y de igual manera tampoco le era dable al marido prestar su "consentimiento" en escritura pública o testamento (vías reconocidas en el entonces precepto vigente) para que su viuda pudiera disponer del embrión (o preembrión) crioconservado. Sin embargo, el propio autor reflexionaba sobre la paradoja que se creaba en el sentido de que lo que podría hacer una mujer sola, ajena a la formación del embrión, al no haber contribuido con su óvulo, esto es, pedir que se le implantara in utero, no lo pudiera hacer precisamente la mujer que había aportado el óvulo, siendo ella la madre biológica del embrión. En todo caso, rechaza la aplicación analógica, pues no encuentra la identidad de razón que predica el artículo 4.2 del Código Civil, ya que la aplicación de tal artículo hubiera supuesto alentar la creación de embriones sobrantes, dando al traste con el espíritu de la norma, que en todo caso lo toleraba como mal menor, pero no como principio informante. ${ }^{31}$

Por el contrario, para Femenía López, a pesar de los errores conceptuales en los que incurre, ${ }^{32}$ la omisión del legislador de 1988 sobre el supuesto de transferencia de embriones post mortem no obedeció a una exclusión voluntaria, sino a un descuido y ello lo sustenta en el plano de igualdad en el tratamiento que el artículo 1.1 daba a todas las técnicas de reproducción humana asistida, sin privilegiar una en detrimento de las otras y en que su utilización debía propugnarse en el tipo de patología padecida, y no por un

${ }^{31}$ Vid. J. E. Bustos Pueche, El derecho civil ante el reto..., Op. cit., pp. 174-176. A juicio del autor, lo cual en cierta medida es contradictorio con su posición doctrinal tan reticente, sólo admitía la posibilidad de una transferencia post mortem de los embriones el supuesto de un matrimonio que habiéndose sometido a un procedimiento de fecundación in vitro, estando ya a punto la transferencia de embriones, pidiera una suspensión temporal de su aplicación por indisposición pasajera, viaje inaplazable o fuerza mayor de la mujer y durante ese lapso muriera el hombre, supuesto en el cual defendía el derecho de la mujer a recibir el embrión y que el hijo nacido fuera matrimonial, no ex artículo 9 de la LTRA, sino ex artículo 15 de la Constitución.

${ }^{32}$ Vid. supra, nota 28. 
régimen jurídico distinto. ${ }^{33}$ En todo caso, las posiciones no fueron nunca pacíficas. Olvido, o no, del legislador, trátese de omisión, de descuido o de gazapo normativo, requería un tratamiento pormenorizado, si bien soy del criterio que la transferencia post mortem de los embriones nunca estuvo prohibida, un razonamiento a fortiori nos hubiera dado la razón. Si se permitía una fecundación post mortem, o sea, si se reconocía en el artículo 9 la figura del concepturus, con las consiguientes implicaciones en terrenos filiatorios y sucesorios, cómo entonces no iba a ser posible la tutela o protección del nasciturus, pues sea un preembrión o un embrión, es un ser un humano in fieri que merece toda la protección jurídica, a partir de la tuición reconocida en el artículo 29 del Código Civil. ${ }^{34}$

A pesar de los criterios adversos que hoy se puedan seguir defendiendo, ${ }^{35}$ creo acertada la posición del legislador del $2006 .{ }^{36}$ El preembrión o el

\footnotetext{
${ }^{33}$ Vid. P. J. Femenía López, Status jurídico civil..., Op. cit., pp. 279-281, y concretamente en nota 97. ${ }^{34}$ Esta posición fue abrazada por R. Gómez-Ferrer Sapiña, “Técnicas de reproducción asistida...”, $O p$. cit., p. 212, quien incluso consideró innecesaria una regulación pormenorizada en la Ley 35/1988; a su juicio si se regulaba la fecundación post mortem, la lógica indicaba que "una vez producido los embriones, e implantados los necesarios para asegurar razonablemente el embarazo (Art. 4), aunque fallezca el marido, la mujer puede pedir la transferencia embrionaria, porque su marido ya consintió, y ya en vida de él había sido concebido el que tras la gestación será hijo suyo, considerándose el preembrión como nasciturus para todos los efectos que le sean favorables y entre otros el tan importante de su derecho a la vida y que sus padres -especialmente si son los genéticos- sean igualmente los legales".

${ }^{35}$ Para Fernando Abellán, "Crítica a la futura ley de reproducción”, en Diario Médico, de 28 de abril de 2006, en fecha en que aún no se había sancionado la ley 14/2006, la novedad que considera lo bastante discutible "es la de presumir el consentimiento del varón a la fecundación post mortem cuando la viuda 'hubiera estado sometida a un proceso de reproducción asistida ya iniciado para la transferencia de embriones constituidos con anterioridad al fallecimiento del marido'. Se está pensando, lógicamente, en un accidente mortal del varón cuando ya la pareja tiene los embriones in vitro pendientes de transferencia o, incluso, criopreservados desde hace tiempo... [...] Por esta vía se va a equiparar el consentimiento ordinario del varón prestado para la realización de la técnica de reproducción con su esposa o compañera, y pensado para tener un hijo en vida, con un supuesto consentimiento para tener un hijo póstumo, sobre lo que sin embargo puede no haberse ni tan siquiera pronunciado jamás el difunto. [...] El que un varón quiera tener un hijo en vida no puede decirse que sea necesariamente equivalente a que lo desee también si piensa que va a morir. Es más, probablemente muchos varones preferirian a buen seguro no tener un hijo del que no van a poder ocuparse, que va a nacer sin padre. No obstante, tal y como se prevé en la norma, aun en el citado supuesto de opinión contraria, la decisión se hace recaer en la viuda, lo que puede resultar especialmente controvertido si el fallecido tuviera otros hijos de una previa relación matrimonial a los que afectará la decisión por motivos hereditarios.” Empero, parece obviar el autor que el legislador pretende ofrecer al nasciturus extracorpóreo un tratamiento lo más homogéneo posible en comparación con el nasciturus in utero. En todo caso cuando se procrea un hijo no se piensa en la muerte, pero el varón sabe que ésta está latente y puede sobrevenir. No por ello la humanidad ha dejado de pensar en la perpetuación de la especie.

${ }^{36}$ Es dable apuntar que con matices diferentes, aun con un tono más conservador, el legislador portugués en su primera ley sobre reproducción médicamente asistida de 26 de julio del 2006, a pesar de proscribir la inseminación post mortem, sí que permitió la transferencia de aquellos embriones anteriormente creados en el ámbito de un "proyecto parental claramente establecido por escrito antes del fallecimiento del padre", según la terminología legal (artículo 22.3). 0 sea, autoriza la transferencia al útero materno de embriones resultantes de una fertilización in vitro efectuada en vida de su esposo o
} 
embrión no son un concepturus, sino un nasciturus, y como tal debe ser tratado, tenga existencia in utero o extracórporea. Sería discriminatorio que el primero fuera protegido en el orden patrimonial y concretamente sucesorio, y el segundo no, por el hecho de no estar en el útero materno. En todo caso, no se trataría ni tan siquiera de un superpóstumo, sino de un póstumo. Por ese motivo creo entender el animus legislatoris implícito en el postulado del artículo 9.2, segundo párrafo, de la LTRA al enunciar: "Se presume otorgado el consentimiento a que se refiere el párrafo anterior cuando el cónyuge supérstite hubiera estado sometido a un proceso de reproducción asistida ya iniciado para la transferencia de preembriones constituidos con anterioridad al fallecimiento del marido." ¿En qué se basa el legislador para presumir el "consentimiento"? Sencillamente en que quien se somete a la aplicación de las técnicas de reproducción humana asistida, lo hace de la misma manera que quien practica el acto sexual con la intención de procrear vía natural. Se asume el riesgo de tener un hijo o varios, si el embarazo es múltiple, sin que quepa ética y jurídicamente seleccionar el número de hijos que en cada embarazo se busca. Si se pretendía tener un único hijo y el embarazo es gemelar, se aceptan ambos. Lo contrario sería asumir una posición utilitarista o, en todo caso, dar prevalencia a la economía personal o doméstica, y especular sobre los gastos que un advenimiento múltiple de hijos pudiera conllevar. Si se acude a las técnicas de reproducción humana asistida y, concretamente, a la FIVTE, también cabe el riesgo de un embarazo múltiple, pero a la vez, aun así, cabe la posibilidad, precisamente por el carácter asistido de la procreación y de la implantación de los preembriones en el útero, que queden preembriones "sobrantes", los cuales pueden ser dados a parejas que lo necesiten o crioconservados. Si el progenitor asumió el riesgo que la técnica médica supone y ya ha procreado varios preembriones, no hay razón entonces para, con trato discriminatorio y egoísta, el legislador derive como consecuencia que su esposa, en caso de fallecimiento de aquél, no pueda llevar a buen fin el desarrollo ulterior de ese nasciturus, ser humano in fieri, que merece nacer. Recuérdese que, a diferencia del supuesto, contenido en el primer párrafo del artículo 9.2 de la LTRA, ya se trata de un ser concebido, no de un hijo de ultratumba, en consecuencia, de un hijo póstumo, que a diferencia del póstumo clásico, reconocido desde el derecho romano, na-

compañero. Al respecto, vid. Vera Lucía Raposo, "La nueva ley portuguesa sobre reproducción asistida", en Revista Bioética y Derecho, No. 10, abril de 2007, en http://www.ub.es/fildt/revista/pdf/RByD10_ArtVera.pdf, consultado el 28 de mayo del 2007, p. 11. 
cerá eso sí, no en un periodo inferior a los nueve meses, contados desde la muerte del padre, sino en uno superior, pero en todo caso, no mucho más prolongado, pues el plazo del que dispone la viuda para hacerse transferir post mortem los preembriones será el mismo que para la inseminación.

Lo más interesante es determinar si esta presunción goza de naturaleza iuris tantum o de iuris et de iure. Nada establece el legislador, pero a priori, pareciera que se inclina por la segunda, pues al menos del contexto del precepto, no cabe aducir prueba en contrario. En tal situación me pregunto: ¿Quid del varón que en el documento donde expresa su voluntad de someterse a las técnicas de reproducción humana asistida manifiesta su oposición de que la FIVTE se aplique tras su muerte? ¿Tendría en tal caso la esposa derecho a que se le transfiriera el preembrión ya in vitro, o ya crioconservado? ¿Si se tiene derecho a revocar la decisión de someterse a las técnicas, por qué no negarse a que se aplique post mortem la transferencia de preembriones?

Realmente el tema tiene ribetes bien difíciles, aunque no tanto la presunción en sí de la autorización. De modo que en in dubio pro vita, esto es, en caso de duda, que se implante el preembrión y con ello, ya en el medio idóneo para desarrollar su vitalidad, pueda entonces nacer. Cabría objetar que la procreación es obra de dos y si ambos progenitores no están contestes, no sería posible entonces la transferencia post mortem de los preembriones. También pudiera aducirse que, si el varón puede revocar en cualquier tiempo antes de la aplicación de las técnicas, su decisión de someterse a ellas y, de igual manera, su disposición sobre el esperma congelado para que sea transferido incluso después de su muerte, puede objetar que el preembrión le sea transferido a su esposa, en iguales condiciones. Pero ahí radica la diferencia esencial. Creo avizorar en el legislador una marcada intención por proteger al nasciturus: el preembrión no puede tener el mismo tratamiento que el "material genético reproductor masculino", o sea, que el semen; éste pertenece a la persona de la cual fue extraído, quien tiene plena titularidad para disponer de él, como parte de los derechos inherentes de la personalidad de los cuales es titular, entre ellos el derecho sobre el cuerpo, órganos, tejidos y sustancias, pero una vez procreado un ser humano, a causa de la fusión de los gametos masculinos y femeninos, y con ello la constitución de un preembrión, no se tienen idénticos derechos, se trata de un ser humano in fieri, distinto a sus progenitores que merece un trato diferente, respecto a la dignidad que él encierra y por ello el más genuino derecho a nacer, aun con la ausencia 
de su padre, no así de su familia paterna. Estaríamos por tanto ante una situación muy similar a la de la viuda que queda embarazada a la muerte de su esposo y ante el temor de condenar a su hijo a una orfandad, acude al aborto. Quizás para algunos este hecho sí sería condenable, a contrario sensu de aquel a cuyo tenor se le impide al preembrión el desarrollarse en un espacio vital que le permita nacer, por considerarse que la viuda que actúa de esa manera sí que condena al hijo a una orfandad premeditada al solicitar la transferencia preembrionaria post mortem. En todo caso, sería condenar a quien comete una acción por la cual se le priva de nacer a un ser humano, y asentir la actuación de quien prefiere negarse a que el preembrión llegue a buen fin, y vivir en el seno familiar en el que siempre debió vivir. ${ }^{37}$

v. Posibilidad de oue el varón de una pareja de hecho pueda exteriorizar SU VOLUNTAD A TRAVÉS DE LOS MEDIOS FORMALES PREVISTOS EX LEGE.

VALOR dE TítULO dE LEGITIMACIÓN DEL DOCUMENTO EN OUE SE CONTIENE SU "CONSENTIMIENTO" A LOS EFECTOS DE INICIAR EL EXPEDIENTE ESTABLECIDO en el artículo 49 de la Ley del Registro Civil

La posibilidad de practicar una inseminación artificial después de la muerte del varón no es exclusiva para el esposo de la supérstite, sino se hace extensiva también a su compañero de hecho, sin que la norma, al igual que la contenida en la ley abrogada, exija otros requerimientos, de tal modo que, aunque no haya estado en la mens legislatoris, cualquier "pareja" improvisada pudiera acceder como tal a las técnicas, evadiendo así la mujer el anonimato de la donación prescrito en el artículo 5.5, en tanto su "pareja" no sería sino una persona que haría la función de donante "elegido", justo a la medida de sus deseos, para procrear un bebé a su gusto, con los rasgos fenotípicos pretendidos; claro que no tendría las "posibilidades" de la mujer sola de crear a su antojo una familia monoparental, lo cual dificultaría que alguien se prestare para ello, pues con su autorización asumiría la paternidad. Empero, en la viña del Señor todo es posible.

Cabe reseñar que, tratándose de una filiación extramatrimonial, la Ley

\footnotetext{
${ }^{37}$ Una tesis que se defiende en este sentido es la de entregar los preembriones en lo que eufemísticamente se le ha llamado "adopción prenatal". En tales circunstancias, habría que evaluar con psicólogos qué es preferible: si vivir en el seno familiar, aun sin la figura del padre, pero sí con la familia paterna consanguínea, o con una familia adoptiva. Parto del supuesto que en ambas familias estén dadas las óptimas condiciones para desarrollar una armónica relación filial y parental.
} 
confiere a la voluntad declarada a través de los medios formales previstos ex lege el valor de título de legitimación a los efectos de iniciar el expediente gubernativo establecido ex artículo 49 de la Ley del Registro Civil. Tal precepto permite la inscripción de la filiación extramatrimonial a través de un expediente gubernativo aprobado por el juez de primera instancia, siempre que exista escrito indubitado del padre o de la madre en que expresamente reconozca la filiación. Así, la norma le confiere a la autorización para que la compañera more uxorio se insemine aun después de la muerte de su pareja, el valor de un reconocimiento anticipado de filiación, aunque expresamente no lo disponga. ${ }^{38}$ Se dice y con razón, que el reconocimiento del nondum conceptus no debe conllevar reparo alguno, en tanto a posteriori "se pone en marcha, dentro del plazo legal previsto, el iter fecundante y llega a formarse el nasciturus. Sería un reconocimiento válido, pero supeditado a la verificación de la concepción del hijo procedente del compañero fallecido" ${ }^{39}$ De no ser así, no cabría proceder directamente a la inscripción de la filiación, cuando la inseminación haya tenido éxito, después de la muerte del progenitor masculino. En todo caso, cabría el ejercicio de la acción judicial de reclamación de paternidad, claro por quien tenga interés en ello, dado que al momento de ser concebido y nacer el superpóstumo, su progenitor ya ha fallecido, en tanto ése es el supuesto normativo reconocido en el artículo 9.3 de LTRA. ${ }^{40}$

\section{V.I. ¿LA PRESUNCIÓN DE "CONSENTIMIENTO" PARA LA TRANSFERENCIA DE PREEMBRIONES POST MORTEM TAMBIÉN ES APLICABLE EN PAREJAS DE HECHO?}

A pesar de que el legislador no se pronuncia expresamente para dar respuesta a este interrogante, la afirmativa se impone. Es cierto que el sentido literal del artículo 9.3 de la LTRA no nos indica sino que: "El varón no unido por vínculo matrimonial podrá hacer uso de la posibilidad prevista en el apartado anterior...", lo cual no hace entender otro particular, que el varón, no cónyuge, tiene idéntico derecho de disponer del semen congelado con efectos post mortem, a favor de su compañera de hecho, a través de las vías que el artículo 9.2, primer párrafo, dispensa. No hay pronuncia-

\footnotetext{
${ }^{38}$ Con tal parecer, M. Alonso Pérez, Comentarios..., Op. cit., xil1, 2º , pp. 23-25 y la doctrina española que allí cita.

${ }^{39}$ Según expresa el propio profesor M. Alonso Pérez, Comentarios..., Op. cit., X111, 2º p. 24.

${ }^{40}$ Para M. Cárcaba Fernández, Los problemas jurídicos..., Op. cit., p. 88, dicho documento constituiría un principio de prueba en el ejercicio de tal acción, en la que se solicite la investigación de la paternidad.
} 
miento sobre el particular de si la presunción de "consentimiento" para la transferencia de preembriones post mortem también le resulta aplicable, pero a estas alturas, entender lo contrario, supondría un absurdo. Si le cabe procrear post mortem, cómo no presumirse también su autorización a transferir al útero de su compañera de hecho el preembrión ya constituido, aun después de su muerte. Si se ha aceptado que su compañera de hecho se someta a las técnicas, se ha colaborado con la extracción del semen y, en consecuencia, con la formación de preembriones, lo más lógico será asumir las consecuencias derivadas de la presunción ex lege reconocida en el artículo 9.2, segundo párrafo, de la Ley. Interpretar lo contrario, supondría ofrecer un trato discriminatorio, infundado, en desmedro del nasciturus extracorpóreo fruto de una unión de hecho, en comparación con el procreado en matrimonio, insustentable ante la fuerza expansiva del artículo 15 de la Constitución.

\section{RefERENCIAS}

Abellán, Fernando, "Crítica a la futura ley de reproducción”, en Diario Médico, de 28 de abril de 2006; Alonso Pérez, Mariano, en Comentarios al Código Civil y Compilaciones forales, tomo xIII, volumen $2^{\circ}, 2^{a}$ edición, dirigidos por Manuel Albaladejo y Silvia Díaz Alabart, Edersa, Madrid, 1998; Alonso Herreros, Diego, "El documento de voluntades anticipadas. Análisis de la ley holandesa sobre eutanasia", en Revista Jurídica de Catalunya, año cIII, No. 2, 2004; Álvarez Lata, Natalia, "Cuestiones sobre el contenido atípico del testamento", en http://www.redadultosmayores.com.ar/buscador/files/BIOET005. pdf, consultado el 28 de mayo de 2007; Andorno, Roberto, "Regulación legal de las técnicas de reproducción asistida. Síntesis de la legislación europea y comentario de dos proyectos de ley presentados al senado argentino", en Revista Persona, No. 57, en http://www.revistapersona.com.ar/Persona57/ 57Andorno.htm, consultado el 11 de junio del 2007; Bustos Pueche, José Enrique, El derecho civil ante el reto de la nueva genética, Dykinson, Madrid, 1996; Cárcaba Fernández, María, Los problemas jurídicos planteados por las nuevas técnicas de procreación humana, Bosch, Barcelona, 1995; Domínguez, Juan, "Quiero tener un huérfano", Revista Época, 2003-2-13, en http://www. mujernueva.org/articulos/articulo.phtml?id=2683\&ttd=0\&tse=ANA, consultado el 28 de mayo del 2007; Femenía López, Pedro J., Status jurídico civil del embrión humano, con especial consideración al concebido in vitro, Mc Craw Hill-Ciencias Jurídicas, Madrid, 1999; Fernández Gallardo, Iñigo, “Algunos aspectos sobre la nueva ley de reproducción asistida", en El Derecho, EDo, 2006/273469; Fernández del Moral Domínguez, Lourdes, Autonomía privada 
y testamento en derecho común. Contribución al estudio de las disposiciones testamentarias atipicas, Comares, Granada, 1996; Gómez-Ferrer Sapiña, Rafael, "Técnicas de reproducción asistida humana y derecho de sucesiones", en Revista Jurídica del Notariado, No. 13, enero-marzo, 1995; Jordano Barea, Juan B., El testamento y su interpretación, Comares, Granada, 1999; Navarro Michel, Mónica, "El documento de voluntades anticipadas (el mal llamado 'testamento vital')", en La Notaría, Revista del Colegio de Notarios de Cataluña, No. 2, febrero de 2003; Pérez Gallardo, Leonardo B., "El acto jurídico testamentario. Contenido e interpretación”, en Derecho de Sucesiones, bajo su coordinación, tomo II, Félix Varela, La Habana, 2004; Pou Ampuero, Felipe, “Testamento vital: declaración de voluntades anticipadas”, en Revista Jurídica del Notariado, No. 42, abril-junio 2002; Raposo, Vera Lucía, "La nueva ley portuguesa sobre reproducción asistida”, en Revista Bioética y Derecho, No. 10, abril del 2007, en http://www.ub.es/fildt/revista/pdf/RByD10_ArtVera.pdf, consultado el 28 de mayo del 2007; Requeiro Ibáñez, José Luis, "El testamento vital y las voluntades anticipadas: aproximación al ordenamiento español”, en La Ley, tomo 4, 2002; Roca Trías, Encarna, "Embriones, padres y donantes. La constitucionalidad de ley 35/1988, de reproducción asistida humana, según STc, 116/1999", en Revista Jurídica de Catalunya, Año XCIX, No. 2, Barcelona, 2000; Segura Zurbano, José María, "El testamento vital o de voluntades anticipadas: panorama actual”, en Boletín de Información del Ilustre Colegio Notarial de Granada (segunda época), No. 257, enero del 2003; Silva Sánchez, Jesús María, “Los ‘documentos de instrucciones previas' de los pacientes (artículo 11.1 Ley 41/2002) en el contexto del debate sobre la (in)disponibilidad de la vida”, en revista La Ley, tomo 4/2003; Stanzione, Pasquale, "Procreacióne assistita e categorie civilistiche", en Studi in onore di Pietro Rescigno, II / Diritto privato, I / Persone, famiglia, successioni e propietà, Giuffrè editore, Milano, 1998; Vega M., J. y Martínez Baza, P. "Regulación de la reproducción asistida en el ámbito europeo. Derecho comparado", en http://www.bioeticaweb.com/content/view/275/42/, consultado el 31 de mayo del 2007.

\section{Legislación}

Código Civil del Reino de España, de 6 de octubre de 1888, 24a edición, Tecnos, Madrid, 2005; Ley $N^{\circ}$ 14/2006, de 14 de mayo, sobre técnicas de reproducción humana asistida, EDL, 2006/58980, B0E, 126/2006, de 27 mayo de 2006; Ref. Boletín: 06/09292. 